\title{
Correlation Between Preoperative Gastric Volume and Weight Loss After Laparoscopic Sleeve Gastrectomy
}

Mohamed AbdAlla Salman, (D)
Mostafa Elshazli,' Mohamed Shaaban, ${ }^{2}$ Mohamed Moustafa Esmat, $\mathbb{D}^{3}$ Ahmed Salman, $\mathbb{D}^{4}$ Heba Mahmoud Mohamed Ibrahim, ${ }^{4}$ Mohamed Tourky, (iD ${ }^{5}$ Alaa Helal, ${ }^{5}$ Ahmed Abdelrahman Mahmoud, ${ }^{5}$ Feras Aljarad, (1) ${ }^{6}$ Amr M Ismaeel Saadawy, (iD) ${ }^{7}$ Hossam El-Din Shaaban, (iD ${ }^{8}$ Doaa Mansour ${ }^{\prime}$

'General Surgery Department, Kasr Al Ainy School of Medicine, Cairo University, Cairo, Egypt; ${ }^{2}$ Damietta General Hospital, General Surgery Department, Damietta, Egypt; ${ }^{3}$ Radiology Department, Kasr Al Ainy Faculty of Medicine, Cairo University, Cairo, Egypt; ${ }^{4}$ Internal Medicine Department, Kasr Al AinyFaculty of Medicine, Cairo University, Cairo, Egypt; ${ }^{5}$ General Surgery Department, Great Western Hospital, NHS Foundation Trust, Swindon, UK; ${ }^{6}$ General Surgery Department, Lewisham and Greenwich NHS Trust, London, UK;

${ }^{7}$ Radiology Department, Faculty of Medicine, Ain Shams University, Cairo, Egypt; ${ }^{8}$ Gastroenterology and Hepatology Department, National Hepatology and Tropical Medicine Research Institute, Cairo, Egypt

Correspondence: Mohamed AbdAlla Salman

General Surgery Department, Associate Professor of General Surgery, Kasr Al Ainy School of Medicine, Cairo University, Cairo, Egypt

Tel +00201096263434

Email Mohammed.salman@kasralainy.edu.eg
Purpose: Long-term studies reported inadequate weight loss or weight regain after laparoscopic sleeve gastrectomy (LSG). This study investigated a possible relationship between preoperative gastric volume $(\mathrm{GV})$ measured by $\mathrm{CT}$ volumetry and weight loss one year after LSG.

Methods: This prospective study included 120 patients scheduled for LSG. 3D CT gastric volumetry was done before surgery. The weight loss in the first year was serially recorded. The primary outcome measure was the correlation between preoperative GV and postoperative weight loss after one year. The secondary outcomes were the correlation between preoperative GV and other patients' characteristics as age and body mass index (BMI).

Results: Weight and BMI decreased significantly up to 12 months. The percentage of excess weight loss (\%EWL) at 6 and 12 months was significantly higher than at three months. Preoperative GV was $1021 \pm 253$, ranging from 397 to $1543 \mathrm{~mL}$. GV was not related to sex, age, weight, height, postoperative weight, and BMI.

Conclusion: Preoperative gastric volume cannot predict weight loss one year after LSG. It is not correlated with age, sex, or preoperative weight, and BMI.

Keywords: correlation, gastric volume, weight loss, sleeve

\section{Introduction}

Currently, laparoscopic sleeve gastrectomy (LSG) is the most frequently performed bariatric surgery worldwide. In 2016, it represented $53.6 \%$ of all procedures, according to the International Federation for the Surgery of Obesity and Metabolic Diseases. ${ }^{1}$ Its popularity is attributed to feasibility and satisfactory weight loss outcomes. ${ }^{2}$ From the restrictive perspective, gastric volume (GV) before and after surgery may influence its outcome. The excision of nearly $80 \%$ of the stomach induces early satiety due to the low compliance of the narrow gastric lumen with high intraluminal pressure. ${ }^{3}$ Accordingly, some studies found that postoperative weight regain can be predicted from the resected volume of the stomach during $\mathrm{SG}^{6-8}$ In a prospective study, a resected $\mathrm{GV}$ of $<500$ cubic centimeters predicted early weight regain or treatment failure. ${ }^{4}$ Hanssen et al found an inverse correlation between postoperative $\mathrm{GV}$ and weight loss six months after LSG. ${ }^{5}$ Toro et $\mathrm{al}^{6}$ proposed a resected gastric size of 1200-1600 $\mathrm{mL}$ to achieve a satisfactory weight loss. However, the authors did not find a correlation of variability in specimen volume and compliance with excess body weight loss. ${ }^{6}$ 
Nevertheless, the role of GV in obesity and response to bariatric procedures is not adequately studied. Gastric volume and emptying modify food intake and consequently may influence body weight. It has been shown that in obese persons, fasting GV was larger, and gastric emptying of solids was faster. ${ }^{7,8}$ Delgado-Aros et al reported an association between higher body mass, larger $\mathrm{GV}$, and decreased satiation. ${ }^{9,10}$

However, we found few studies exploring the preoperative gastric volume before LSG as a possible factor that could affect postoperative weight loss. Therefore, this study was designed to investigate a possible relationship between preoperative gastric volume detected by CT volumetry with weight loss one year after laparoscopic sleeve gastrectomy.

\section{Patients and Methods}

This prospective study was conducted during the period between November 2017 and July 2019. The study included 120 patients scheduled for laparoscopic sleeve gastrectomy (LSG). The study was conducted in accordance with the principles of the Helsinki Declaration and Good Clinical Practice. It was approved by the ethics committee of the Cairo University Hospitals. Written informed consent was obtained from all patients participating in this study.

The study included patients 17 to 65 years old, with a body mass index $(\mathrm{BMI})>40 \mathrm{~kg} / \mathrm{m}^{2}$ or BMI $>35 \mathrm{~kg} / \mathrm{m}^{2}$ associated with comorbidity. Patients with a history of stomach cancer, previous gastric surgery, chronic liver disease, previous abdominal exploration, or psychogenic disorders were excluded from the study.

All patients were subjected to thorough history taking and clinical examination. Preoperative laboratory investigations included complete blood count, coagulation profile, liver function tests, kidney function tests, fasting blood sugar, and hepatitis B and C markers. ECG, chest $\mathrm{X}$-ray, and pulmonary function tests were done to assess the chest condition and airways before surgery.

\section{D CT Gastric Volumetry}

3D CT gastric volumetry was done before sleeve gastrectomy. All patients were given oral effervescent granules before the study to ensure gastric distension crucial for acquiring volumetric data. Pouch dimensions were calculated using 3D CT; a proper pouch volume could be calculated using the parameters of height, width, and depth. Pouch volume was expressed in cubic centimeters (cc). Pouch area was calculated as height (or length) times the width, expressed in square centimeters. The method used to calculate pouch area was measured on an anteroposterior radiograph at maximum pouch distention.

\section{Laparoscopic Sleeve Gastrectomy}

Before surgery, enoxaparin $40 \mathrm{IU}$ at the night of the operation and antibiotic prophylaxis with 2 gm of cefazolin within one hour were administered. Surgery was performed under general anesthesia. A crepe bandage was applied to prevent thromboembolism in both legs. The patient was put in a reverse Trendelenburg position. Pneumoperitoneum was established through the insertion of a veres needle. The first trocar $10 \mathrm{~mL}$ for the camera was introduced $18-20 \mathrm{~cm}$ inferior to the xiphoid and patient's left side to the midline then insertion of camera $30^{\circ}$ scope. The second trocar $5-10 \mathrm{~mL}$ for liver retractor was inserted just below the xiphoid from the patient's left side. The third and fourth trocars, $12-15 \mathrm{~mL}$ for the surgeon's working hands, were inserted from the patient's left and right midclavicular line $2 \mathrm{~cm}$ higher than the camera trocar. A fifth trocar for the assistant was inserted from the patient's left axillary line below the costal arch.

The pylorus was identified, and the greater curvature of the stomach was elevated. An advanced bipolar device was used to enter the greater sac via dividing the greater omentum. The greater curvature of the stomach was then dissected free from the omentum and the short gastric blood vessels using the bipolar device. An endoscopic linear cutting stapler was used to staple and transect the stomach serially. Stapling started 4-6 cm from the pylorus till the angle of His done over 36 Fr bougie (Figure 1). Hemostasis was secured, and a tube drain was inserted. Excised stomach was removed, then the ports' sites were closed.

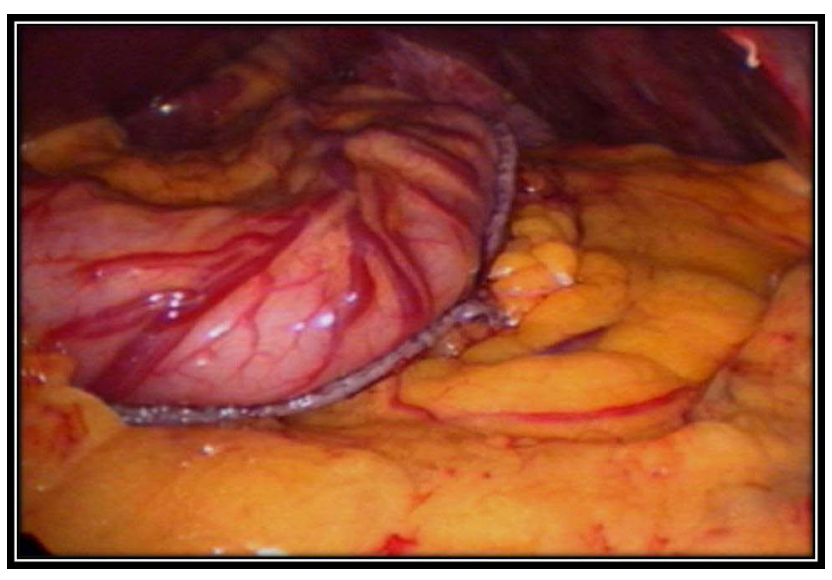

Figure I Sleeve pouch after stapling. 


\section{Postoperative Assessment}

The postoperative complications were recorded after the first follow-up visit on day 7. Subsequent visits were scheduled at weeks 2,3 , and 4 , then months $2,3,6$, and 12. The body weight loss in the first year was recorded serially.

The primary outcome measure was the correlation between preoperative GV and postoperative weight loss after one year. The secondary outcomes were the correlation between preoperative GV and different patients' characteristics as age, sex, and preoperative BMI.

\section{Statistical Analysis}

Statistical analysis was done using IBM $\odot$ SPSS $\odot$ Statistics version 22 (IBMC Corp., Armonk, NY, USA). Numerical data were expressed as mean and standard deviation. Qualitative data were expressed as frequency and percentage. For quantitative data, comparison between two groups was made using independent sample $t$-test Comparison of repeated measures was made using ANOVA for repeated measures followed by Bonferroni test as post-hoc test. Pearson product-moment was used to estimate the correlation between numerical variables. A p-value $<0.05$ was considered significant.

\section{Results}

Table 1 shows the baseline characteristics of the studied group. Comorbidities were recorded in 47 patients $(60.8 \%)$, the most common of diabetes mellitus (DM).

Table I Baseline Characteristics of the Whole Studied Group $(n=120)$

\begin{tabular}{|l|c|}
\hline & Value \\
\hline Age (years) & $34.0 \pm 9.7$ \\
\hline Gender (Male/Female) & $54 / 66$ \\
\hline Body mass index $\left(\mathrm{kg} / \mathrm{m}^{2}\right)$ & $42.4 \pm 3.1$ \\
\hline Comorbidities & \\
Diabetes Mellitus & $24(20.0 \%)$ \\
Hypertension & $13(10.8 \%)$ \\
Hyperlipidemia & $4(3.3 \%)$ \\
Spine problems & $2(1.7 \%)$ \\
Lumbar disc prolapse & $1(0.8 \%)$ \\
Obstructive sleep apnea & $1(0.8 \%)$ \\
Knee osteoarthritis & $1(0.8 \%)$ \\
Sleep apnea & $1(0.8 \%)$ \\
Ischemic heart disease & $I(0.8 \%)$ \\
\hline
\end{tabular}

Note: Data are presented as mean \pm SD or number (\%).
Table 2 Change of Weight and Body Mass Index Throughout the Follow-Up Period $(\mathrm{n}=119)$

\begin{tabular}{|l|c|c|}
\hline & Weight $\mathbf{( k g )}$ & Body Mass Index $\left(\mathbf{k g} / \mathbf{m}^{2}\right)$ \\
\hline Preoperative & $119.2 \pm 12.5$ & $42.5 \pm 3.1$ \\
3 Months & $100.2 \pm 12.2$ & $35.7 \pm 3.3$ \\
6 Months & $83.1 \pm 8.8$ & $29.6 \pm 1.9$ \\
12 Months & $69.2 \pm 7.8$ & $24.6 \pm 1.0$ \\
\hline
\end{tabular}

Note: Data are presented as mean \pm SD.

One patient suffered a severe postoperative leak and died in hospital. The follow-up data are presented for the remaining 119 patients. Table 2 shows that weight and BMI decreased significantly through the follow-up period up to 12 months ( $p<0.001$ for all comparisons). The percentage of excess weight loss (\%EWL) during the follow-up period is shown in Table 3. \%EWL at six months was significantly higher than that at three months. Also, the \%EWL at 12 months was significantly higher than that at 3 and 6 months.

Preoperative GV was $1021 \pm 253$, ranging from 397 to $1543 \mathrm{~mL}$. It was comparable in males $(1012 \pm 263 \mathrm{~mL})$ and females $(1030 \pm 248, p=0.703)$. Also, GV was not correlated with age, weight, height, postoperative weight, and BMI, or \%EWL (Table 4).

One patient experienced staple line leakage one week postoperatively and was controlled by an endoscopic stent and intraabdominal drains after laparoscopic exploration and irrigation. But the patient died two weeks after reexploration due to respiratory distress because of aspiration during a vomiting attack. Two patients suffered from bleeding and were managed by conservative measures and resuscitation by blood transfusion.

\section{Discussion}

The effectiveness of bariatric surgery has been emphasized over the past few decades. LSG has evolved into the most frequent bariatric procedure in many areas globally, with increasing evidence on its efficacy and safety. ${ }^{11,12}$ LSG achieves durable long-term weight loss with significant

Table 3 Percentage of Excess Weight Loss (\%EWL) Throughout the Follow-Up Period $(\mathrm{n}=119)$

\begin{tabular}{|l|c|c|}
\hline & \%EWL & p-value* \\
\hline 3 Months & $33.4 \pm 8.2$ & \\
6 Months & $62.6 \pm 7.1$ & $<0.001$ \\
12 Months & $86.2 \pm 5.1$ & $<0.001$ \\
\hline
\end{tabular}

Notes: Data are presented as mean $\pm \mathrm{SD}$. *Compared to $\mathrm{EWL}$ at three months. 
Table 4 Correlation of Preoperative Gastric Volume with Patients' Characteristics and Postoperative Weight Loss $(n=119)$

\begin{tabular}{|l|c|c|}
\hline & Correlation Coefficient & p-value \\
\hline Age & 0.095 & 0.302 \\
Height & 0.177 & 0.054 \\
Preoperative Weight & 0.170 & 0.064 \\
Weight after 3 months & 0.162 & 0.079 \\
Weight after 6 months & 0.149 & 0.106 \\
Weight after 12 months & 0.165 & 0.103 \\
Body mass index & 0.002 & 0.987 \\
BMl after 3 months & 0.024 & 0.796 \\
BMI after 6 months & -0.026 & 0.780 \\
BMI after I2 months & 0.172 & 0.086 \\
\%EWL after 3 months & -0.046 & 0.620 \\
\%EWL after 6 months & 0.051 & 0.582 \\
\%EWL after 12 months & -0.141 & 0.126 \\
\hline
\end{tabular}

Abbreviations: BMI, body mass index; \%EWL, percentage of excess weight loss.

comorbidities resolution, especially type- 2 DM. ${ }^{13}$ However, multiple physiologic, anthropometric, and social factors affect the outcome of bariatric procedures. For example, a BMI above $50 \mathrm{~kg} / \mathrm{m}^{2}$ may be associated with a poor outcome than lower BMIs. ${ }^{14}$ Long-term studies reported an appreciable frequency of inadequate weight loss or even weight regain after $\mathrm{LSG}^{15,16}$ with an estimated failure rate of $10 \%$ to $30 \% .{ }^{17}$ Therefore, many investigators tried to identify factors that might predict weight loss in a trial to improve bariatric surgery outcomes. ${ }^{18}$

Weight loss after LSG appears to be multifactorial, despite volume restriction being the key factor. ${ }^{19,20}$ The impact of residual sleeve volume after LSG on weight loss has been investigated. A high residual gastric volume (RGV) three years after LSG was a risk factor for failure. ${ }^{21}$ A recent meta-analysis of five studies showed that variations in RGV could explain up to $26.3 \%$ of the variability in weight loss following LSG. ${ }^{22}$ A meta-analysis of four studies demonstrated that a smaller bougie diameter was associated with a better weight loss than the larger diameter bougies. ${ }^{23}$ Technically, LSG encompasses a longitudinal transection of most gastric fundus, body, and antrum directed by a bougie. ${ }^{24}$ However, disparities have been reported in the bougie size and the distance from the pylorus as the point to start resection. ${ }^{10,11}$ But, the resected GV remains a non-standardized variable in all cases. So, many studies investigated the association between resected GV and weight loss after $\mathrm{LSG}^{25-30}$ yet their findings were controversial.
Besides, stomach volume may vary widely among different patients. One study found that stomach size was affected by sex, BMI, and age. The greater curvature was significantly longer in patients with more severe obesity. ${ }^{31}$ Another study compared stomach size and volume in obese and non-obese individuals and found no significant difference. Moreover, patients with obesity had significantly smaller greater curvatures. The authors reported that BMI was negatively correlated with the length of greater curvature and positively correlated with that of the lesser curvature. ${ }^{32}$ Thus, the resected stomach volume can also vary and is not an appropriate predictor of the success of LSG.

Therefore, we investigated any possible correlation between the preoperative GV measured by CT volumetry before LSG and weight loss in the first postoperative year in this study. We found widely variable preoperative GV ranging from 397 to $1543 \mathrm{~mL}$, which was not correlated with age, sex, weight, or height. However, it did not predict postoperative weight and BMI or \%EWL.

In contrast to former beliefs, we did not find a correlation between GV and BMI. Previous studies reported that obese individuals tend to have a larger stomach capacity than non-obese, ${ }^{33,34}$ but the findings were based on subjective measures. They depend on the maximal tolerable volume with an intragastric balloon rather than the more objective intragastric pressure or compliance. A larger antral volume in fasting obese individuals was also demonstrated by Kim et $\mathrm{al}^{35}$ in adults using single-photon emission computed tomography and in children by Chiloiro et al using ultrasonography. ${ }^{36}$ More recently, Elbanna et al found a positive correlation between preoperative GV and BMI and body weight. ${ }^{14}$ These authors used three-dimensional (3D) CT. In the present study, we also used 3D CT, a feasible noninvasive method that provides a standardized $\mathrm{GV}$ with visualization of an easy-to-understand image by patients and surgeons. ${ }^{37}$ Like the current study, Mohamed et al reported a nonsignificant correlation between preoperative GV and body weight. ${ }^{38}$ The authors of the present study frequently observed a relatively small stomach in patients subjected to bariatric surgery.

No correlation between the preoperative GV and weight loss at 12 months postoperatively is the main finding of this study. This was concordant with the previous two studies investigating the relation between preoperative GV and weight loss after LSG. Elbanna et al found no correlation between preoperative GV and the \%EWL six 
months after LSG. ${ }^{14}$ Similarly, Mohamed et al did not show a direct impact of $\mathrm{GV}$ on weight reduction after LSG. $^{38}$

These findings support the notion of other non-restrictive mechanisms for weight loss in LSG, like postoperative hormonal and gastric emptying changes. Studies reported a postoperative reduction of ghrelin hormone levels, an appetite-stimulating hormone mainly produced by glands in the stomach fundus. ${ }^{39}$ It is hypothesized that the increased gastric emptying rate increases secretion of some gut hormones like GLP-1 that induce more rapid satiety. ${ }^{40,41}$ Rapid gastric emptying causes faster intestinal transit, contributing to weight loss and improvement of type-2 DM. ${ }^{42,43}$

We did not use preoperative screening and treatment for Helicobacter pylori as the findings of Gianluca Rossetti et al suggest that Helicobacter pylori infection seems not to influence postoperative outcome of patients operated of laparoscopic sleeve gastrectomy. ${ }^{44}$

This study had some limitations; it missed the residual $\mathrm{GV}$ and pouch volume, but other studies evaluate them. ${ }^{45}$ In conclusion, the preoperative GV cannot predict weight loss one year after LSG. Preoperative GV is not correlated with age, sex, or preoperative weight, and BMI. Long-term follow-up may reveal a predictive value of $\mathrm{GV}$ of the outcome of LSG and other bariatric surgery. 3D CT gastric volumetry appears to be an accurate tool for studying gastric size and structure before bariatric surgery. We advocate that LSG is not simply a restrictive procedure working through reducing stomach volume. Other mechanisms for weight loss operate more and need to be proved by more extensive research.

\section{Disclosure}

The authors report no conflicts of interest in this work.

\section{References}

1. Angrisani L, Santonicola A, Iovino P, et al. IFSO Worldwide Survey 2016: primary, Endoluminal, and Revisional Procedures. Obes Surg. 2018;28:3783-3794. doi:10.1007/s11695-018-3450-2

2. Shi X, Karmali S, Sharma AM, Birch DW. A review of laparoscopic sleeve gastrectomy for morbid obesity. Obes Surg. 2010;20:11711177. doi:10.1007/s11695-010-0145-8

3. Huang R, Ding X, Fu H, Cai Q. Potential mechanisms of sleeve gastrectomy for reducing weight and improving metabolism in patients with obesity. Surg Obes Relat Dis. 2019;15(10):1861-1871. doi:10. 1016/j.soard.2019.06.022

4. Weiner RA, Weiner S, Pomhoff I, Jacobi C, Makarewicz W, Weigand G. Laparoscopic sleeve gastrectomy-influence of sleeve size and resected gastric volume. Obes Surg. 2007;17:1297-1305. doi:10.10 07/s11695-007-9232-x
5. Hanssen A, Plotnikov S, Acosta G, et al. 3D volumetry and its correlation between postoperative gastric volume and excess weight loss after sleeve gastrectomy. Obes Surg. 2018;28:775-780. doi:10.1007/s11695-017-2927-8

6. Toro JP, Patel AD, Lytle NW, et al. Observed variability in sleeve gastrectomy volume and compliance does not correlate to postoperative outcomes. Surg Laparosc Endosc Percutan Tech. 2015;25:324330. doi:10.1097/SLE.0000000000000181

7. Acosta A, Camilleri M, Shin A, et al. Quantitative gastrointestinal and psychological traits associated with obesity and response to weight-loss therapy. Gastroenterology. 2015;148(537-546.e4). doi:10.1053/j.gastro.2014.11.020.

8. Vazquez Roque MI, Camilleri M, Stephens DA, et al. Gastric sensorimotor functions and hormone profile in normal weight, overweight, and obese people. Gastroenterology. 2006;131:1717-1724. doi:10.1053/j. gastro.2006.10.025

9. Delgado-Aros S, Cremonini F, Castillo JE, et al. Independent influences of body mass and gastric volumes on satiation in humans. Gastroenterology. 2004;126:432-440. doi:10.1053/j.gastro.2003.11.007

10. Delgado-Aros S, Camilleri M, Castillo EJ, et al. Effect of gastric volume or emptying on meal-related symptoms after liquid nutrients in obesity: a pharmacologic study. Clin Gastroenterol Hepatol. 2005;3:997-1006. doi:10.1016/S1542-3565(05)00285-5

11. Ponce J, DeMaria EJ, Nguyen NT, Hutter M, Sudan R, Morton JM. American Society for Metabolic and Bariatric Surgery estimation of bariatric surgery procedures in 2015 and surgeon workforce in the United States. Surg Obes Relat Dis. 2016;12:1637-1639. doi:10.1016/j.soard.2016.08.488

12. Emile SH, Elfeki H, Elalfy K, Abdallah E. Laparoscopic sleeve gastrectomy then and now: an updated systematic review of the progress and short-term outcomes over the last 5 years. Surg Laparosc Endosc Percutan Tech. 2017;27:307-317. doi:10.1097/SLE.0000000000000418

13. Gu L, Huang X, Li S, et al. A meta-analysis of the medium- and long-term effects of laparoscopic sleeve gastrectomy and laparoscopic Roux-en-Y gastric bypass. BMC Surg. 2020;20:30. doi:10.1186/s12893-020-00695-x

14. Elbanna H, Emile S, El-Hawary GE-S, et al. Assessment of the correlation between preoperative and immediate postoperative gastric volume and weight loss after sleeve gastrectomy using computed tomography volumetry. World J Surg. 2019;43:199-206. doi:10.1007/s00268-018-4749-9

15. Boza C, Daroch D, Barros D, León F, Funke R, Crovari F. Long-term outcomes of laparoscopic sleeve gastrectomy as a primary bariatric procedure. Surg Obes Relat Dis. 2014;10:1129-1133. doi:10.1016/j. soard.2014.03.024

16. Felsenreich DM, Langer FB, Kefurt R, et al. Weight loss, weight regain, and conversions to Roux-en-Y gastric bypass: 10-year results of laparoscopic sleeve gastrectomy. Surg Obes Relat Dis. 2016;12:1655-1662. doi:10.1016/j.soard.2016.02.021

17. Weiner RA, Theodoridou S, Weiner S. Failure of laparoscopic sleeve gastrectomy-further procedure? Obes Facts. 2011;4(Suppl 1):42-46. doi: $10.1159 / 000327343$

18. van Hout GCM, Verschure SKM, van Heck GL. Psychosocial predictors of success following bariatric surgery. Obes Surg. 2005;15:552-560. doi:10.1381/0960892053723484

19. Ferrer-Márquez M, García-Díaz JJ, Moreno-Serrano A, et al. Changes in Gastric Volume and Their Implications for Weight Loss after Laparoscopic Sleeve Gastrectomy. Obes Surg. 2017;27:303309. doi:10.1007/s11695-016-2274-1

20. Barbiero G, Romanucci G, Ortu V, et al. Relationship between gastric pouch and weight loss after laparoscopic sleeve gastrectomy. Surg Endosc. 2016;30:1559-1563. doi:10.1007/s00464-015-4377-5

21. Deguines J-B, Verhaeghe P, Yzet T, Robert B, Cosse C, Regimbeau J$\mathrm{M}$. Is the residual gastric volume after laparoscopic sleeve gastrectomy an objective criterion for adapting the treatment strategy after failure? Surg Obes Relat Dis. 2013;9:660-666. doi:10.1016/j. soard.2012.11.010 
22. Singla V, Aggarwal S, Aggarwal S, Gupta M, Singh D. Correlation of weight loss with residual gastric volume on computerized tomography in patients undergoing sleeve gastrectomy: a systematic review. Clin Obes. 2020;10:e12394. doi:10.1111/cob.12394

23. Wang Y, Yi X-Y, Gong L, Li Q, Zhang J, Wang Z. The effectiveness and safety of laparoscopic sleeve gastrectomy with different sizes of bougie calibration: a systematic review and meta-analysis. Int J Surg. 2018;49:32-38. doi:10.1016/j.ijsu.2017.12.005

24. Clinical Issues Committee of the American Society for Metabolic and Bariatric Surgery. Updated position statement on sleeve gastrectomy as a bariatric procedure. Surg Obes Relat Dis. 2010;6:1-5. doi:10.1016/j.soard.2009.11.004

25. Singh JP, Tantia O, Chaudhuri T, Khanna S, Patil PH. Is Resected Stomach Volume Related to Weight Loss After Laparoscopic Sleeve Gastrectomy? Obes Surg. 2014;24:1656-1661. doi:10.1007/s11695014-1250-x

26. Obeidat FW, Shanti HA, Mismar AA, Elmuhtaseb MS, Al-Qudah MS. Volume of Resected Stomach as a Predictor of Excess Weight Loss After Sleeve Gastrectomy. Obes Surg. 2014;24(11):1904-1908. doi:10.1007/s11695-014-1330-y

27. McCracken J, Steinbeisser M, Kharbutli B. Does Size Matter? Correlation of Excised Gastric Specimen Size in Sleeve Gastrectomy to Postoperative Weight Loss and Comorbidities. Obes Surg. 2018;28:1002-1006. doi:10.1007/s11695-017-2975-0

28. Du X, Luo R, Chen Y, Peng B, Hu J, Cheng Z. Resected gastric volume has no influence on early weight loss after laparoscopic sleeve gastrectomy. Surg Obes Relat Dis. 2018;14:129-135. doi:10.1016/j.soard.2017.11.005

29. Pawanindra L, Vindal A, Midha M, Nagpal P, Manchanda A, Chander J. Early postoperative weight loss after laparoscopic sleeve gastrectomy correlates with the volume of the excised stomach and not with that of the sleeve! Preliminary data from a multi-detector computed tomography-based study. Surg Endosc. 2015;29:29212927. doi:10.1007/s00464-014-4021-9

30. D’Ugo S, Bellato V, Bianciardi E, Gentileschi P. Impact of Resected Gastric Volume on Postoperative Weight Loss after Laparoscopic Sleeve Gastrectomy. Gastroenterol Res Pract. 2019;2019:1-5. doi:10.1155/2019/3742075

31. Lee E-G, Kim T-H, Huh Y-J, et al. Anthropometric Study of the Stomach. $J$ Gastric Cancer. 2016;16:247-253. doi:10.5230/ jgc.2016.16.4.247

32. Csendes A, Burgos AM. Size, volume and weight of the stomach in patients with morbid obesity compared to controls. Obes Surg. 2005;15:1133-1136. doi:10.1381/0960892055002158

33. Granström L, Backman L. Stomach distension in extremely obese and in normal subjects. Acta Chir Scand. 1985;151:367-370.
34. Geliebter A. Gastric distension and gastric capacity in relation to food intake in humans. Physiol Behav. 1988;44:665-668. doi:10.1016/0031-9384(88)90333-2

35. Kim DY, Camilleri M, Murray JA, Stephens DA, Levine JA, Burton DD. Is there a role for gastric accommodation and satiety in asymptomatic obese people? Obes Res. 2001;9:655-661. doi:10.1038/ oby. 2001.89

36. Chiloiro M, Caroli M, Guerra V, Lodadea Piepoli A, Riezzo G. Gastric emptying in normal weight and obese children-an ultrasound study. Int $J$ Obes Relat Metab Disord. 1999;23:1303-1306. doi:10.1038/sj.ijo.0801071

37. Kim SH, Keum B, Choi HS, et al. Stomach Volume Assessment Using Three-dimensional Computed Tomography Gastrography for Bariatric Treatment. Obes Surg. 2020;30:401-406. doi:10.1007/ s11695-019-04189-5

38. Mohamed AENY, Elfeshawy MS, Sokker EAA. Role of CT Gastric Volumetric Study in Sleeve Gastrectomy. Egyptian J Hospital Med. 2019;76:3724-3735. doi:10.21608/ejhm.2019.39921

39. Karamanakos SN, Vagenas K, Kalfarentzos F, Alexandrides TK. Weight loss, appetite suppression, and changes in fasting and postprandial ghrelin and peptide-YY levels after Roux-en-Y gastric bypass and sleeve gastrectomy: a prospective, double blind study. Ann Surg. 2008;247:401-407. doi:10.1097/SLA.0b013e318156f012

40. Tong J, D'Alessio D. Give the receptor a brake: slowing gastric emptying by GLP-1. Diabetes. 2014;63:407-409. doi:10.2337/db131764

41. Chambers AP, Smith EP, Begg DP, et al. Regulation of gastric emptying rate and its role in nutrient-induced GLP-1 secretion in rats after vertical sleeve gastrectomy. Am J Physiol Endocrinol Metab. 2014;306:E424-432. doi:10.1152/ajpendo.00469.2013

42. Gagner M. Faster gastric emptying after laparoscopic sleeve gastrectomy. Obes Surg. 2010;20:964-965. doi:10.1007/s11695-010-0086-2

43. Michalsky D, Dvorak P, Belacek J, Kasalicky M. Radical resection of the pyloric antrum and its effect on gastric emptying after sleeve gastrectomy. Obes Surg. 2013;23:567-573. doi:10.1007/s11695-0120850-6

44. Rossetti G, Moccia F, Marra T, et al. Does helicobacter pylori infection have influence on outcome of laparoscopic sleeve gastrectomy for morbid obesity? Int $J$ Surg. 2014;12(Suppl 1):S68-71. doi:10.1016/j.ijsu.2014.05.051

45. Salman MAA, Elshazly M, Ragab AA, Hegazy TO. Relationship between the resected stomach volume and early postoperative weight loss following laparoscopic sleeve gastrectomy. Int Surg J. 2018;5 (4):1180-1185. doi:10.18203/2349-2902.isj20181098
International Journal of General Medicine

\section{Publish your work in this journal}

The International Journal of General Medicine is an international, peer-reviewed open-access journal that focuses on general and internal medicine, pathogenesis, epidemiology, diagnosis, monitoring and treatment protocols. The journal is characterized by the rapid reporting of reviews, original research and clinical studies across all disease areas. The manuscript management system is completely online and includes a very quick and fair peer-review system, which is all easy to use. Visit http://www.dovepress.com/ testimonials.php to read real quotes from published authors. 